Здесь:Lo - глубина внутреннего отверстия толкателя,L1 - максимальное растяжение пружины,L2=L1-h- минимальное сжатие пружины;ход золотникаһ $=\mathrm{L}-\mathrm{b}$ (головка золотника).

Подбор пружины можно также осуществить по специальной номограмме (рис. 5) с использованием конструктивной схемы (рис. 4), а также по данным таблиц 1 и 2.

Таблий 1.

Размеры и усилия пружсин

\begin{tabular}{|c|c|c|c|c|c|}
\hline $\begin{array}{c}\text { Длины и } \\
\text { усилия }\end{array}$ & Пружина 1 & Пружина 2 & Пружина 3 & Пружина 4 & Пружина 5 \\
\hline $\boldsymbol{L}_{\mathbf{1}}$,мM & \multicolumn{5}{|c|}{28,5} \\
\hline $\boldsymbol{L}_{\mathbf{2}}, \mathrm{MM}$ & \multicolumn{2}{|c|}{21,3} & 25 & 23 & 21 \\
\hline $\boldsymbol{F}_{\mathbf{1}}, \mathrm{H}$ & 18,1 & 14 & 14,4 & 5,71 & 18,2 \\
\hline $\boldsymbol{F}_{\mathbf{2}}, \mathrm{H}$ & 52,6 & 72 & 52,5 & 50,3 & 45,28 \\
\hline
\end{tabular}

Размеры толкателей

\begin{tabular}{|c|c|c|}
\hline Толкатели & Lo, мм & h, мм \\
\hline № 1 & 10,5 & 7,5 \\
\hline №2 & 8,5 & 5,5 \\
\hline №3 & 6,5 & 3,5 \\
\hline
\end{tabular}

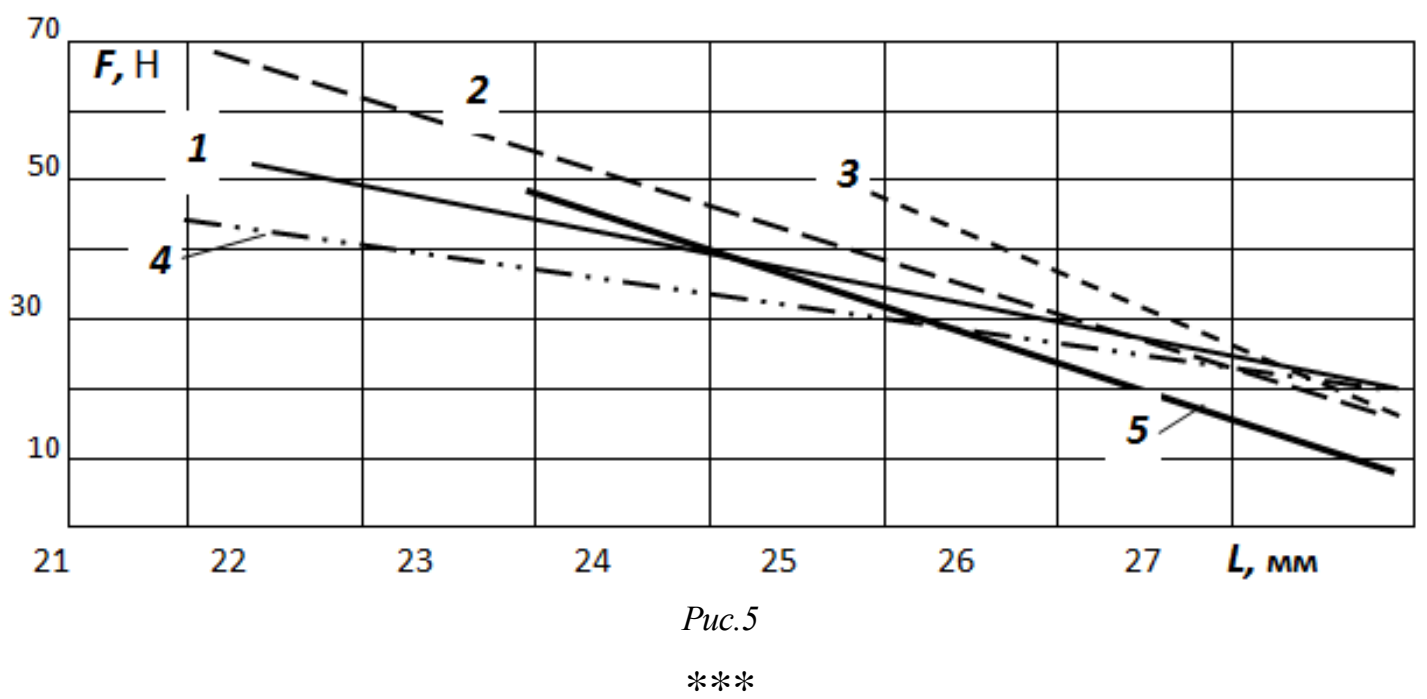

1. Чмиль В.П. Гидропневмопривод строительной техники. Конструкция, принцип действия, расчет: Учебное пособие.- СПб.: Издательство «Лань», 2011 - 320 с.

2. Каталог гидравликиОАО «Пневмостроймашина». Екатеринбург: 2005.

\title{
Кузнецов А.А., Мурзин А.Н. \\ Анализ течения жидкости в тягоизмерительном устройстве поршневого типа для авиационного двигателя с большой тягой
}

\section{Аннотация}

В статье рассмотрено конструктивное исполнение гидростатической мессдозы (ГМ). Выделен основной элемент мессдозы, влияющий на гидравлическое сопротивление - щели между поршнем и цилиндром. В работе рассмотрено вихревое течение в мессдозе в ламинарном и турбулентном режимах (получены в ANSYS FLUENT). В статье приведена схема гидростатической мессдозы и отражены результаты эксперимента. 
В настоящее время существует возможность моделировать процессы, происходящие в работе гидростатических динамометров, с использованием современного программного комплекса, что позволит получить данные, наиболее приближённые к реальным характеристикам проектируемого динамометра.

Важность данного исследования заключается в том, что гидростатический динамометр имеет возможность использования в различных отраслях техники. Гидростатические опоры обладают повышенной несущей способностью и жесткостью. Вместе с тем гидростатические подшипники являются опорами с изменяемой жесткостной характеристикой. Это позволяет использовать их в качестве амортизаторов и противоударных устройств.

Своевременность разработки заключается в том, что отечественными конструкторскими бюро ведутся разработки двигателей с тягой в 35 тонн. Для этого целесообразно создание тягоизмерительного устройства с повышенной точностью измерения. Следовательно, цель работы состоит в повышения чувствительности тягоизмерительного устройства и точности замера. Необходимо уменьшить трение между рабочими поверхностями поршня и цилиндра. Для этого необходимо моделирование течение рабочей жидкости в цилиндре.

Принцип действия гидравлических мессдоз основан на преобразовании реактивной силы в давление жидкости, которое регистрируется приборами. Сила тяги, действуя на поршень, создает давление в цилиндре, пропорциональное прилагаемому усилию.

Для повышения чувствительности динамометра и точности замера необходимо уменьшить трение между рабочими поверхностями поршня и цилиндра.

На рис. 1 представлена конструктивная схема гидравлической мессдозы, в основу которого положен гидростатический принцип центрирования.

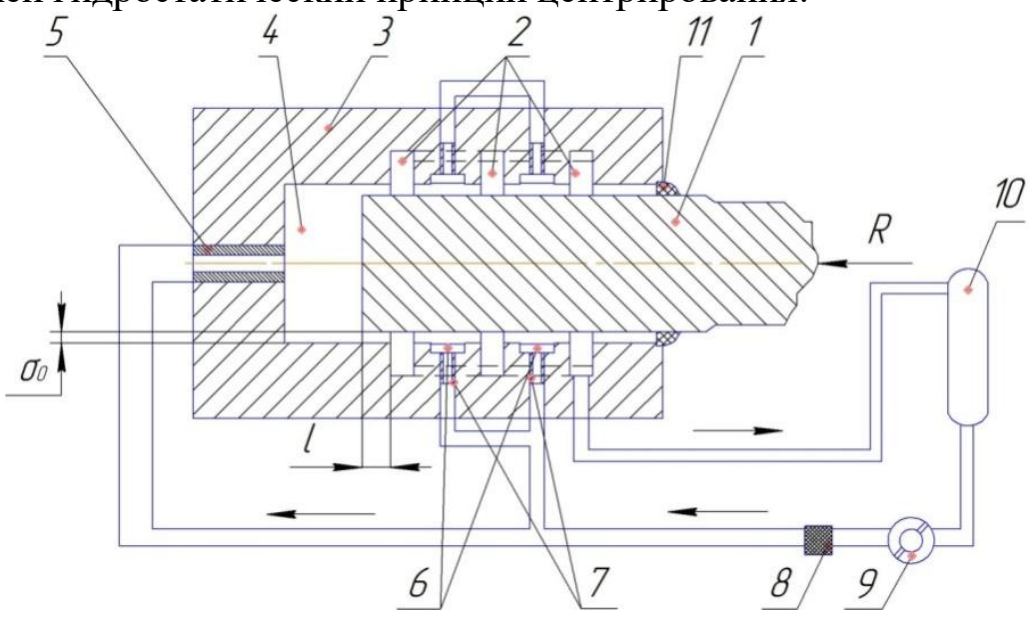

Рисунок 1 - Схема гидростатической мессдозы

1 - поршень, 2 - выходные каналь, 3 - ичлиндр, 4 - основная камера динамометра (осевая гидростатическая опора), 5- дроссель, 6- -иентрирующие камеры (два радиальньх изентрирующих гидростатических подшипников), 7 - дроссели гидростатического подиипника, 8- фильтр, 9 -насос, 10 -бак, 11 - гибкая мембрана.

В настоящей работе приведены результаты исследования статических характеристик гидростатического динамометра.

Рабочая жидкость от внешнего источника давления через дросселирующий элемент 5 подводится в рабочую камеру 4, а через дросселирующий элемент 7 в центрирующие камеры $6 . \mathrm{B}$ качестве дросселирующего элемента целесообразно использовать подводящую трубку небольшого диаметра для обеспечения определенного режима течения. По кольцевой щели с диаметральным зазором $2 \delta 0$ и длиной 1 жидкость поступает в дренажную полость 2, выполненную в цилиндре 3. Давление жидкости в камерах 6 воспринимают радиальную нагрузку, действующую на поршень, препятствуя 
перекосу, заклиниванию и заеданию поршня в цилиндре. Замер величины и колебания тяги осуществляется прибором.

Рассматриваемый гидростатический динамометр обладает следующими преимуществами:

1) трение при трогании с места и в процессе работы ничтожно мало и соответствует чисто жидкостному трению, чем достигается повышенная чувствительность динамометра;

2) при обеспечении одинаковых режимов течения жидкости на входе через дросселирующие элементы и на выходе через кольцевую щель характеристики динамометра не зависят от внешних условий и рода жидкости;

3) в качестве рабочего тела можно использовать практически любую жидкость (воду, керосин, масло, воздух и т.д.);

4) пониженные требования к материалам и механической обработке поршня и цилиндра (класс точности и чистота практически будут определятся только радиальным зазором, который значительно влияет на расход жидкости).

Основным недостатком данного устройства является сравнительно большой расход жидкости, что приводит к некоторому усложнению гидравлической системы. Но в стендовых условиях это вполне допустимо.

Давление жидкости в рабочей камере 4 будет изменятся в зависимости от длины щели 1, которая в свою очередь определяется действующей нагрузкой.

По формуле (1), рассчитаем давление в рабочей камере:

$$
W=p_{k} * F,
$$

где $\mathrm{W}$ - действующая нагрузка, в данном случае тяга двигателя равна $35 \mathrm{Tc}$, $\mathrm{p}_{\mathrm{k}}$ - давление в рабочей камере,

$\mathrm{F}$ - площадь поршня.

Примем диаметр поршня равный 10 см.

$$
\begin{aligned}
& p_{k}=\frac{W}{F}, \\
& F=\frac{\pi D^{2}}{4}, \\
& p_{k}=\frac{W * 4}{\pi D^{2}},
\end{aligned}
$$

$$
p_{k}=437 \text { бар. }
$$

Для дальнейшего анализа рабочего давления будем учитывать следующее, что металлические рукава, которые применяются в качестве обвязки, имеют ограничения по давлению рабочей среды. Для данной конструкции гидростатических динамометров примем сильфон стандартного исполнения ВМЗ 07315-11 МР015.1 (однооплеточный) с внутренним диаметром dy $=6$. Данный рукав выдерживает максимальное давление Рmax $=160$ бар при температуре $200 \mathrm{C}$.

Примем диаметр поршня равный 20 см.

$$
p_{k}=109 \text { бар. }
$$

Поршень диаметром 20 см подходит нам по условия пропускной способности и прочности (по рабочему давлению) металлического рукава. После нахождения диаметра поршня построим расчетную модель, которая будет выглядеть следующей образом (рис. 2). 

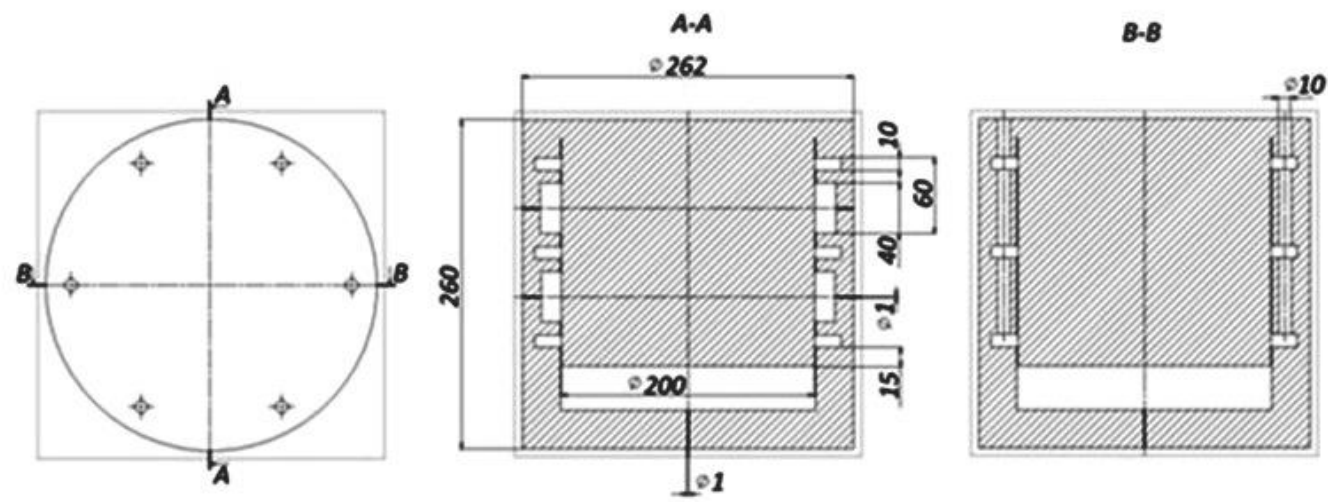

Рисунок 2 - Исследуемое тягоизмерительное устройство

Исходными данными для создания геометрической модели расчетной области являются входные дросселирующие каналы, заданные пользователем и выходные каналы, позволяющие получать устойчивые решения при расчетных исследованиях. На рис. 3 показана трехмерная модель исследуемой мессдозы.

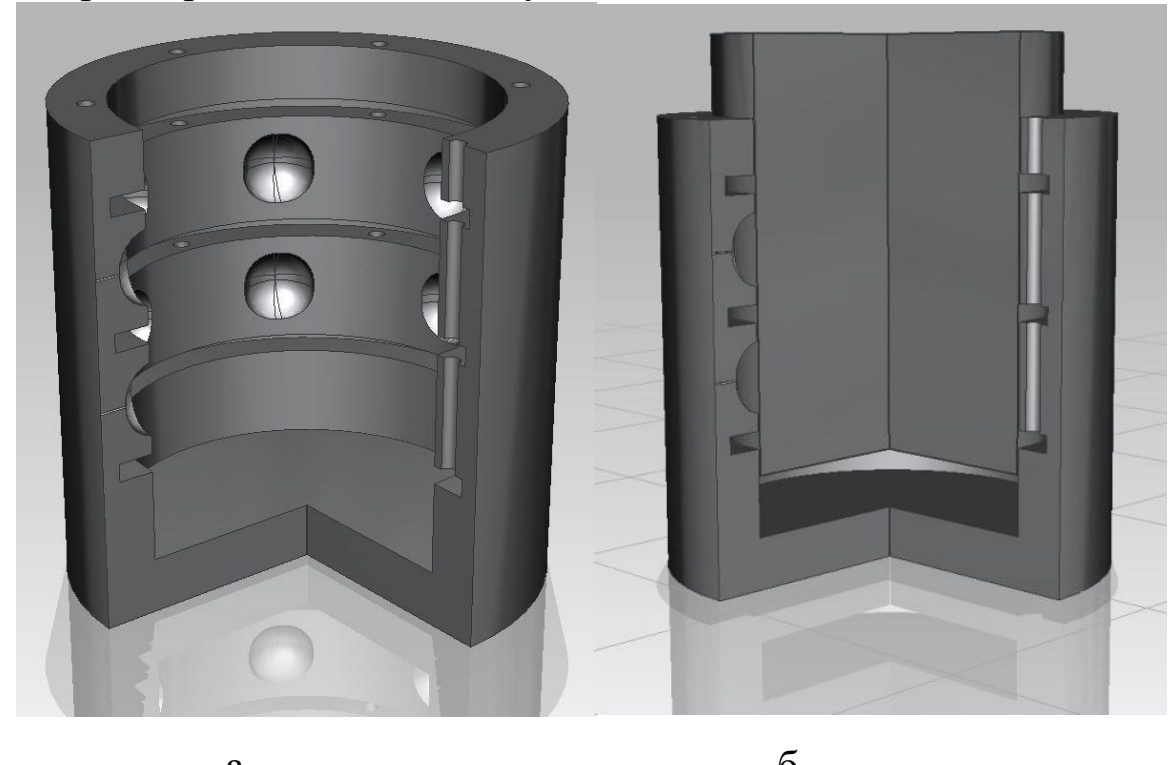

a

6

Рисунок 3 - Трехмерная модель исследуемой мессдозы a-модель цчилиндра; б-модель изилндра с пориеннем

Дальнейшее исследование рабочего процесса в мессдозе происходит в программном комплексе Ansys под управление платформы Workbench. В рассматриваемом примере выбираем тип анализа: Fluid Flow (CFX).

В качестве граничных условий используются: течение жидкости ламинарное в первом расчете, во втором турбулентное, полное давление на входе в расчетную область; статическое давление, равное атмосферному давлению на выходе из расчетной области. В качестве рабочего тела используется масло АМГ-10.

Масло АМГ-10 предназначено для гидросистем авиационной и наземной техники, работающей в интервале температур окружающей среды от -60 до $+55^{\circ} \mathrm{C}$. Масло АМГ-10 производится на основе глубокодеароматизированной низкозастывающей фракции, получаемой из продуктов гидрокрекинга смеси парафинистых нефтей и состоящей из нафтеновых и изопарафиновых углеводородов. Содержит загущающие и антиокислительные присадки, а также специальный отличительный органический краситель.

Технические характеристики масла: 
Кинематическая вязкость

Плотность

$$
\begin{array}{r}
10 \mathrm{MM}^{2} / \mathrm{c} \\
850 \mathrm{\kappa r} / \mathrm{M}^{3}
\end{array}
$$

В результате расчета получены следующие результаты. На рис. 4 представлены сечения мессдозы, на которых изображены вектора направлений потока жидкости в моделях. Особо хотелось отметить течение рабочей жидкости во входных центрирующих камерах (рис. 5, а - ламинарное течение, б - турбулентное течение).

На рис. 5 видим, что в местах около дросселя возникают вихревые течения жидкости. Завихрения занимают почти всю центрирующею камеру. Но при турбулентном течение (см. рис. 5,б), в отличие от ламинарного течения (см. рис. 5,a) наружный радиус меньше.

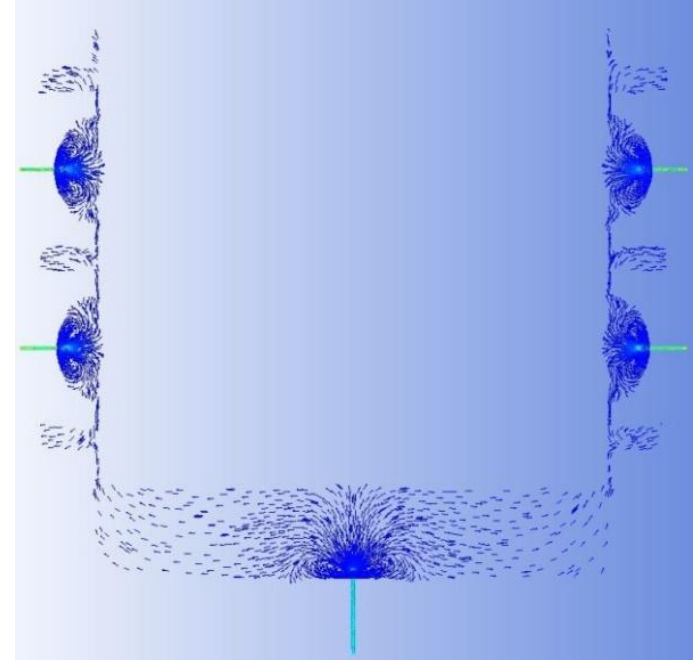

$a$

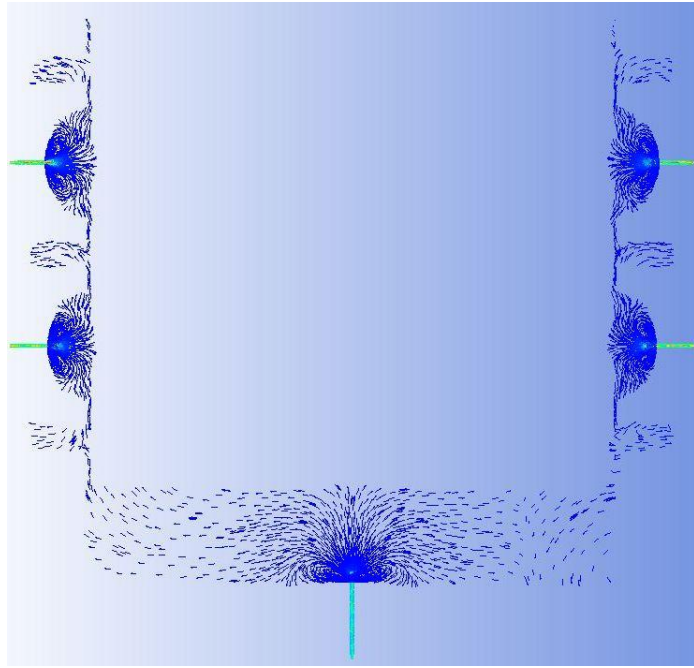

$\sigma$

Рисунок 4-Вектора направлений потока жидкости в модели $a$-ламинарном течение; б- турбулентное течение

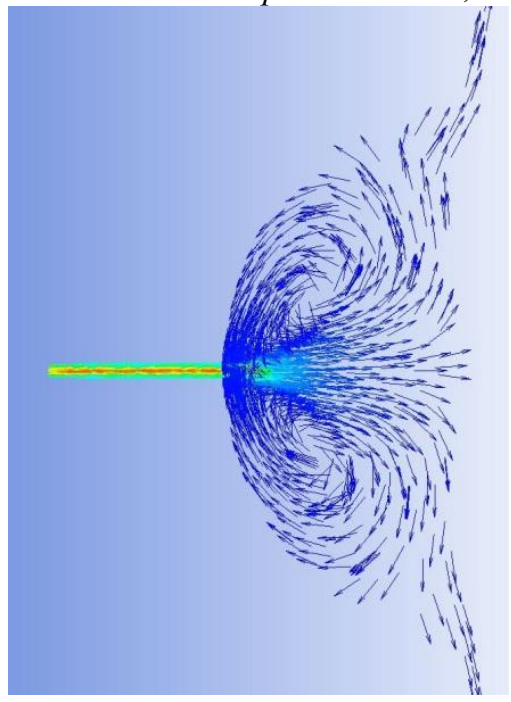

$a$

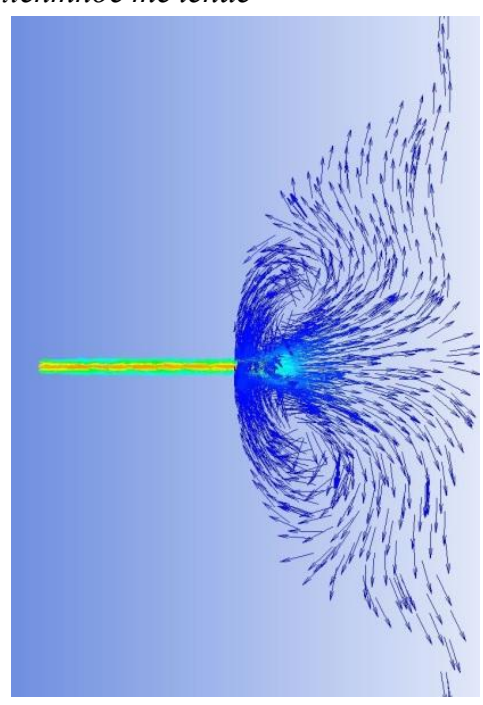

6

Рисунок 5 - Вектора направлений потока жидкости в модели $a$-ламинарном течение; б- турбулентное течение

Завихрения влияют на точность измерения тяги, и нужно избавляться от них. В дальнейшем будет проанализировано влияние завихрений на точность измерения тяги, и соотношений глубины центрирующей камеры к ее длине и величине радиального зазора ГСМ, формы центрирующих камер и других факторов. 